\title{
Challenges of Digitalization of Agrarian Sector in terms of Human Development
}

\author{
Anatolii Ostapchuk, Kateryna Alekseieva, Tetiana Artiukh, Alona Zorgach, Lesia Zaburanna
}

\begin{abstract}
The article substantiates the digitization of the agrarian sector as a major trend that determines not only the economic but also human development. Digitalization is defined as the process of transforming information into a digital form, and such a process which more or less touches absolutely all spheres of life making first of all qualitative changes and influencing human development itself. In Ukraine where the agrarian sector is in fact the locomotive of economic development, its digitalization becomes the main task that needs practical application. Today significant achievements of Ukrainian agricultural companies in the direction of digitalization can be observed but a large number of problems still need to be addressed and remain challenges for the future. First of all the focus should be on combining the use of digital technologies with the appropriate training of workers of all levels capable of working in the new environment. Then it is possible to ensure both the fulfillment of economic goals and the achievement of human development goals. To do this Government supporting programs for the agrarian sector's digitalization at all levels are needed.
\end{abstract}

Key words: agrarian sector, challenges of digitalization, digitalization, human development.

\section{INTRODUCTION}

Digitalization of agrarian sector in Ukraine and other countries leads to changes in the ways of producing of agrarian goods and services and of the ways of food security holding. The digitalization itself possesses a great potential in terms of the environmental, economic, social and human development. Simultaneously there are challenges and risks to arise which can lead to expected and unexpected consequences in the long run. Disparities in access to digital Ukraine and in other countries can provide their economic activities in particular in agriculture. Lack of e-literacy among people in the villages can cause resistance to innovations among people and even provoke crises while the large agrarian companies are oriented at implementing digital technologies in order to cut their costs and improve productivity. It is understandable that those who do not

Revised Version Manuscript Received on October 15, 2019.

Anatolii Ostapchuk, Dean of the Faculty of Agrarian Management, National University of Life and Environmental Sciences of Ukraine, Kyiv, Ukraine.(Email: aostpchuk@ukr.net)

Kateryna Alekseieva, As. Professor of Production and Investment Management Department, National University of Life and Environmental Sciences of Ukraine, Kyiv, Ukraine. .(Email: aostpchuk@ukr.net)

Tetiana Artiukh, As. Professor of Department of Management named after prof. J.S. Zavadskyi, National University of Life and Environmental Sciences of Ukraine, Kyiv, Ukraine. .(Email: tad1tad2@ukr.net)

Alona Zorgach, Senior lecturer of Department of Management named after prof. J.S. Zavadskyi, National University of Life and Environmental Sciences of Ukraine, Kyiv, Ukraine (Email: zorgach.a@ gmail.com)

Lesia Zaburanna, Professor of Department of Management named after prof. J.S. Zavadskyi, National University of Life and Environmental Sciences of Ukraine, Kyiv, Ukraine ((Email: zaburanna@ gmail.com) technologies cause the disparities in the way people in

manage to implement digital technologies into the production process are at risk of being left behind in terms of productivity and aspects of economic and human development. To meet the fool potential of digital transformation of the agrarian sector there is a need in implementing of well-thought economic supportive policy stimulating first of all appropriate human development.

\section{LITERATURE REVIEW}

Problems of digitalization of agrarian sector are constantly in the field of view of theorists. In particular, various aspects of the general process of digitalization have been fundamentally explored in the work of the Negroponte $N$. (1995), who was the first to use the word "digitalization" and to give definition to it.

A number of Ukrainian researchers have recently become devoted to the problems of digitalization in different branches and sectors of the domestic economy. In particular, attempt to find a creative solution to the problem of forecasting the new workplaces in the industrial sector of Ukrainian economy was done in the work of Kozhemiakina S., Cherkasov A., Reznik N., Zhuravka O., Mazurov S. (2018). Digitalization of economic relations as a factor of improving the business processes at enterprises was investigated by $L$. Lazebnyk (2018).

Attention of the Ukrainian scholars is also being kept by innovation and digitalization problems of concrete directions of the agrarian production within the sector. For instance, the challenges for growth of oilseeds and the following exchange of them at the world market have been studied by N. Reznik, S. Gupta, O. Sakovska, A. Ostapchuk, R. Levkina (2019).

Despite the importance of the research that has already been carried out by scientists there are some aspects of digitalization of economy left without attention. That is why the topic of the current research was considered to be relevant and actual and the challenges of digitalization of agrarian sector in terms of human development have been considered in the article.

The most important tasks of the article are substantiation of the digitalization itself in current conditions, its impact on the human development; demonstrating the crucial role of the agrarian sector in the Ukrainian economy and outline the present achievements in digitalization of it; and working out the main solutions to the challenges that arise in the process of digitalization of the agrarian sector.

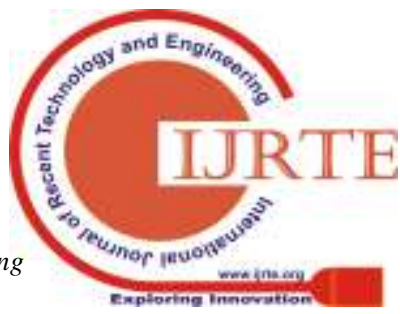




\section{METHODOLOGY}

To achieve the formulated goal of the research and to fulfill the stated tasks a set of well-known scientific methods and techniques have been used. The method of logic synthesis has been applied in order to well-ground theoretically the importance of studying the challenges of digitalization of the agrarian sector in terms of human development. Using the methods of analysis and synthesis allowed showing the importance the agrarian sector for the economy of Ukraine and the present achievements in the digitalization of it. The method of finding logical connections was used to demonstrate the necessity of simultaneous providing innovations and preparing workers for manipulating them. Method of building schemes and models has been used for a visual representation of results of the research and their schematic representation.

\section{RESULTS}

Nowadays the digital world is included in every aspect of the social and economic life from how people spend their time to how they manage money. The process of digitalization is changing the usual way of communication and entertainment. Information is collected on millions of websites whereas Internet is able to replace television, newspapers and magazines. People are becoming accustomed to using e-mail, social networks and blogs to communicate and share important information; they are now digital consumers who are looking for products and services on-line. According to experts in 2017 the turnover of physical goods and services in e-commerce increased by $30 \%$ and at the end of 2017 amounted to about 50 billion UAH. In 2018 the turnover of physical goods and services in e-commerce reached 65 billion UAH [3]. It speaks about the incorporation of national business into the global tendency to digitalize economic relations.

The term "digital economy" was introduced into scientific circulation in 1995 by the American scientist N. Negroponte [9]. The formation of the concept of a digital economy was the result of the rapid expansion of digitalization processes in all spheres of economic life since the first half of the last century. Already in the first decade of the twenty first century it became clear that only a country which managed to involve digitalization into the economic system could be successful and prosperous. At present, digitalization of the economy has become one of the conditions for prosperity of the country, because all developed market systems of the present day (USA, European countries, and developed countries of Asia) necessarily have accelerated the digital processes. However, this is a concept still interpreted ambiguously. In particular, the digital economy is identified with knowledge, information, or network. In our opinion, the digitalization can be accepted as a process based on information, namely the digitalization of significant amounts of knowledge and data, which leads to qualitative changes in human and economic development. Digitalization in its essence is the process of transforming information into digital form, i.e. "translating" texts, sound and video into language that computers understand.

All aspects of life are being integrated into the virtual space all over the world. Digitalization fundamentally changes business, reducing production costs and increasing labor productivity. Thanks to digitalization there are new directions in marketing able to stimulate products' promotion and new progressive approaches in management of all spheres. It is impossible for some firms to remain competitive in current conditions at the market ignoring digitalization. Everything in a company's management from accounting system to reputation creating is nowadays more or less connected to digitalization.

As for the point of view that digitalization defines not only the economic development trends, but it influences the human development process, it is necessary to mention that it simplifies life of people, raises its quality, creates new working places and consequently changes the way of thinking of people opening the new horizons. These all are proofs of the fact that the most important transformation of our time is happening and can be witnessed. This transformation can be called digitalization of social and economic life of people.

Thinking in macroeconomic parameters in Ukraine the agriculture is one of the most actively developing sectors today and plays a very important social role. It is much connected to human development because of the large quantity of people living in the villages and can be frequently viewed as a social lift for the young people born there. It is a well-known fact, that the Ukrainian economy has experienced many crises, but the agricultural sector has always remained the driver of the economy. There are four main reasons which allowed agrarians to maintain the pace of development of the industry. The first reason is a comparatively favorable geographical position that provides a connection with the whole world. The second one is a fertile land, which makes up two-thirds of the entire territory of Ukraine. The third reason is good weather and climate conditions. And the fourth is people able to work in the fields.

Over the last ten years, the agrarian sector has possessed the top positions of Ukrainian economy. It has made up $10-$ $12 \%$ of Ukrainian GDP (nominal) becoming among TOP-3 largest industries. About $17 \%$ of working force is employed in the sector. In 2017, nominal agricultural GDP reached at USD 11,5 billion in comparison with USD 10,8 billion in $2016(+6 \%)$.[1] A unique feature of the agricultural sector of Ukraine is the availability of a wide variety of natural resources. Among them the agricultural land covers 41,9 million hectares, or $69,4 \%$ of the total territory of Ukraine. In Ukraine's only arable land exceeds the whole land resources of many countries, i.e. 33,3 million hectares are considered to be arable lands. Besides 2,2 million hectares are left on hay; 5,3 million hectares are pastures; 1,1 million hectares are occupied by annual plantings. It is the agricultural sector where, unlike most other sectors of the economy of Ukraine the researchers can observe investment and infrastructure projects, and successful debt restructuring projects, and corporate restructuring, and the activity of donor organizations as well as technical assistance projects. For instance there are such successful projects existing as EBRD and Cargill joint investment project in the construction of a 
grain terminal in the port "Yuzhny", a number of project financing in favor of Ukrainian agricultural companies, successful restructuring of Ukrlandfarming's financial obligations in the amount of about $\$ 600$ million and others. [6]

Thanks to this positive evidence Ukraine has got a products with low added value, i.e. on export of raw production. This is defined by the fact of lack of investments into highly technological production as well as lack of Government stimulating measures towards stimulating of development of such production. Simultaneously large areas to be used for yields rising together with fertile soil quality allow having good results in the raising of the yields and their following selling. It is worth saying that for example in the USA export of corn and soybeans without their processing are also high thanks to the possibilities of their raising. This means that a country that has such vast areas for cultivation and high quality soil in these areas will always have a raw material orientation in agricultural exports. This is not Ukrainian specifics, but a normal world practice.

As for the digitalization in the agricultural sector of Ukraine it should be said that in the very near future global digitalization and automation of all processes in agribusiness is anticipated. This means the use of new technologies and unique large-scale IT solutions. Already today, Ukrainian agricultural companies use of innovations which have no analogues in any other branch of industry of Ukraine.

Serious transformations in the agriculture have been being observed during the last $5-7$ years. Ukrainian agribusiness has reached a qualitatively new level, i.e. the principles of work, approaches are changing, and transparent business models are being built. Prior to this agribusiness was developing quite randomly and haphazardly without due attention on behalf of Government and World organizations. Nowadays when there is a situation of increasing of population of our planet from year to year attention to the agricultural sector all over the world and in particular to agricultural sector of our country with its unique agricultural potential is growing. This makes businessmen of the industry think about introducing innovations, improve technologies and learn how to effectively manage all processes.

Today in the fields of Ukraine the Farming Management System is used, i.e. satellite online monitoring is conducted, GPS navigation, mapping, drones are implemented. There are networks of weather stations, their own research centers. In addition to technical innovations the introduction of IT innovations in agricultural production is actively ongoing.

The majority of the projects oriented at digitalization of the agrarian sector are being done by large agro holdings of Ukraine. For example, Kernel Agro Holding has been introducing an innovative DigitalAgriBusiness software complex at its enterprises since the beginning of 2016. This system has allowed for maximum profit and yield on a single field. The program demonstrates solutions to agronomists, engineers and other departments on the basis of previously developed techniques. The project Digital Agribusiness is an innovative IT solution for providing a total control over the execution of all technological operations; data analysis and effective management of the changes in production. Also an potential to become a world leader in agriculture. Of course the main accent is still being made on the export of the

interesting solution towards digitalization of the production of the agrarian products has been introduced by the MHP company (Ukrainian abbreviation from Myroniv Bread Products). By the way the MHP is one of the minorities of the Ukrainian agrarian producers containing a separate innovative department in its structure. The company develops on its clusters a line of geographic information systems (GIS) that helps to manage an existing land bank. Representatives of the agricultural holding note that this system allows the company to accelerate the ways of data analysis and introduce unique algorithms to effectively implement various user requests.[5]

As a matter of fact, to continue digitalization of the agrarian sector effectively Ukraine is to meet challenges which are partly the challenges met all over the world and partly they are specific for our country. It is crucial to admit that there are two necessary things to make production in the agrarian sector as effective as possible. (Fig.1) These are technologies transformed very often into different digital forms and people trained to use them. In case if people are not ready to use these technologies because of lack of education for example or being reluctant to do this a staff crisis inside the company can occur. History of the world economy knows the events when unqualified workers of big factories used to ruin the new machines to be involved into production in order to keep working places. Of course, in current conditions such bright manifestations of resistance to innovation do not occur whereas the latent resistance to innovations changing too quickly to have time to adjust to them can be observed frequently. For example, it is not new anymore to use tractors working without people or assembly lines fully manipulated only by one trained operator. This helps the agrarian companies to optimize costs, to operate in a new way, to obtain the goods with high added value in the end. But this means having qualified staff able to use and control such technique. This can be either a qualified worker or an agrarian manager of the middle level, but in any case he (or she) should possess practical skills and be ready to work with the new equipment anytime. That is why staff training and education become important factors in practical providing the digitalization process.

There is no need to fight resistance to innovations; people need to be prepared for innovations. The deeper the technologies penetrate the agro-company, the more detailed the change management program should become, which is needed in the company to minimize the shock and stress, to get people perceived that the changes are needed. For example, in the Ukrainian agrarian company Kernel there is a program "mobile agronomist" being introduced to control the logistics. When it was put into production as part of a pilot project in one of the clusters, several representatives of the security personnel were fired because it was too difficult for them to develop the new product. In fact it is not necessary to break people down, but it is important to work with them, explaining that technology makes their work easier and more efficient. But there are people who find it difficult to accept this fact, and then they are to be fired. [4] 
At the same time there are several conditions (basic and enabling) which are to be met necessarily in order transform the agriculture digitally in different contexts. The basic ones can be seen as the minimum conditions needed to implement technology. These are availability, affordability, possibility to connect, different educational programs raising informational skills of people and stimulating Government policies for digital development.

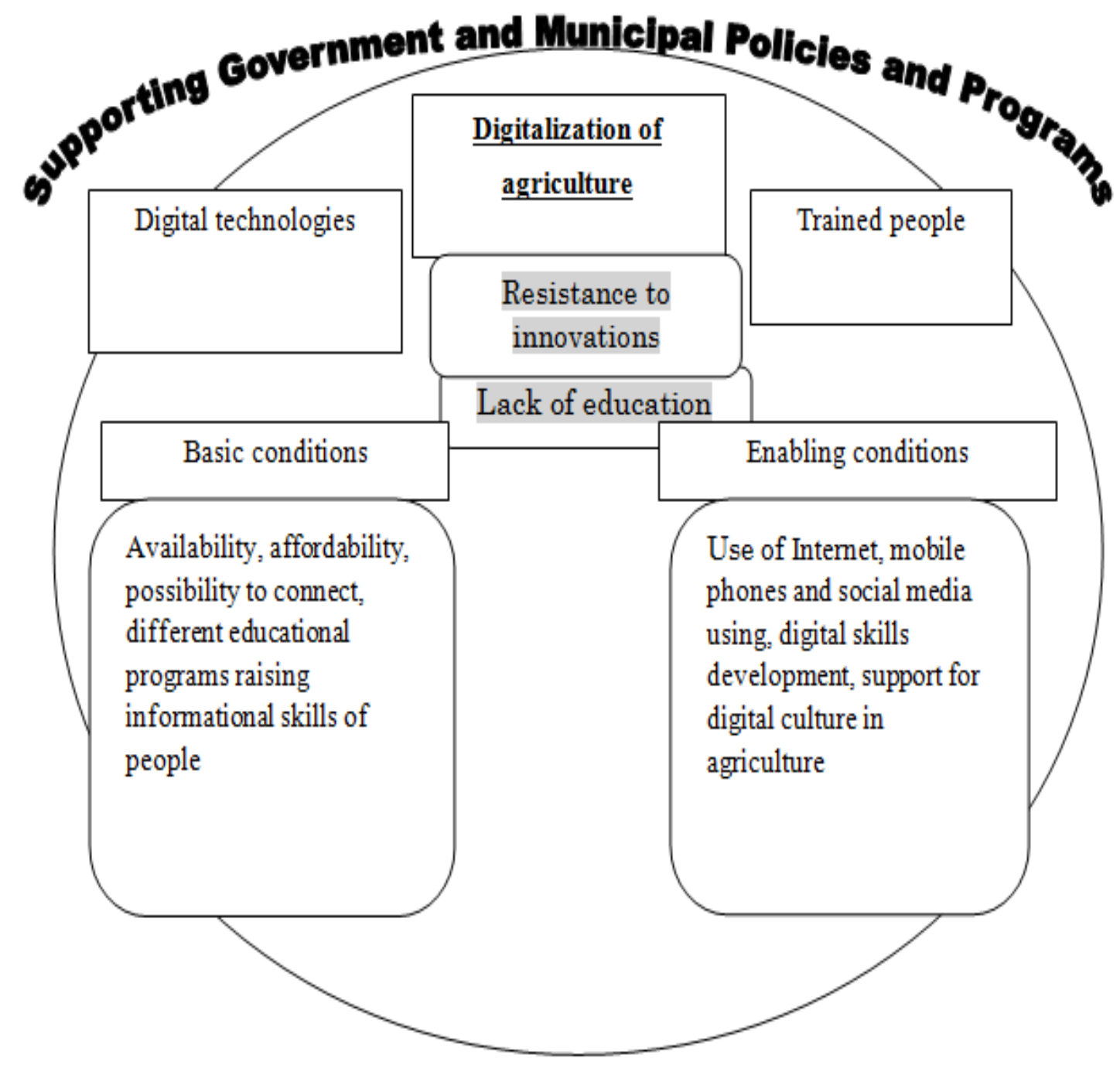

Fig.1. Factors and conditions which define the process of digitalization of agriculture

*Source: created by authors on the basis of [2]

As for the enabling conditions, these are mainly the factors which can lead to adoption of the technologies by wide quantities of people working in the agrarian sector. Among such factors there are such well known things as Internet, mobile phones and social media using, digital skills development, support for digital culture in agriculture. Practically all these factors can be implemented through talent development, sprint programs, incubators using, different accelerator programs introducing. (Fig.1)

People who do not possess basic literacy and numeracy can never be involved into the digitalization process. Fortunately in Ukraine unlike some African and Asian regions this problem is not the one to solve. All Ukrainians both in the cities and in the villages possess basic knowledge and obtain basic education and are often involved into obtaining higher education. In comparison with many countries there are rather high figures of higher education involvement in Ukraine in rural areas though these figures are much lower than those in urban areas (Fig. 2). 


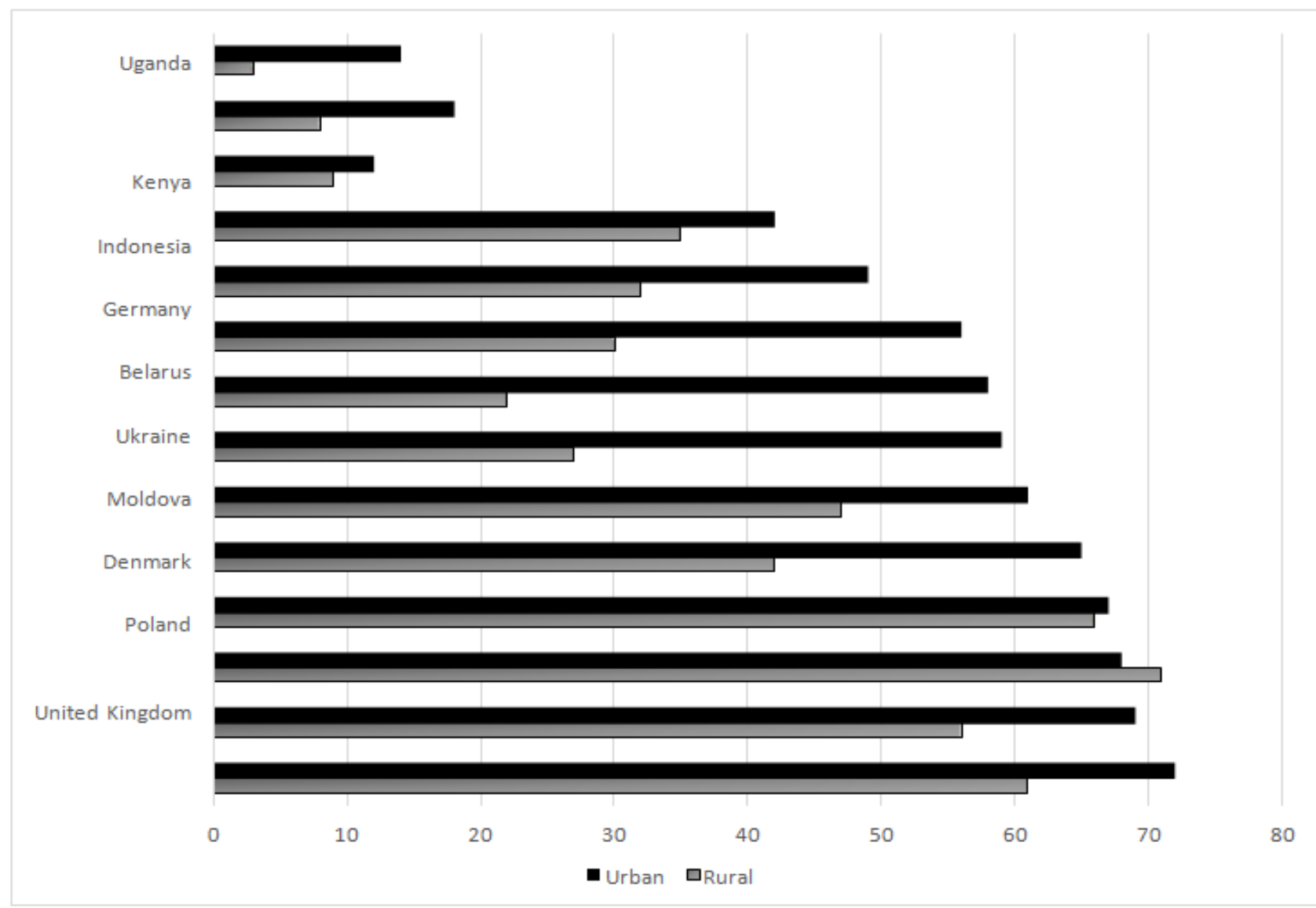

Fig. 2. Higher education involvement by degree of urbanization, \%

* Source: made up by the authors on the basis of [2]

But at the same time the "digital literacy" is really a challenge for people in the rural areas. Basic computer courses have not been integrated yet into primary and secondary education in the villages due to the poor material and technical providing. In comparison with the developed countries where students regularly use advanced technologies and digital skills in their education and day-to-day lives in Ukraine even Internet connection has not been made everywhere.

Besides, very often there can be observed a lack of relevant skills among teachers. The World Bank defines the fact that creating the necessary jobs in agrifood sector while sustaining existing employment in the world will be among the most significant challenges in the process of digitalization of agriculture next 15 years because 1,6 billion people in developing countries will reach working age during the period. [2] Digitalization of the sector is going to change the nature of work drastically as well as demand for labor and skills. The digital literacy will become the main requirement in different jobs in the sector and certainly the level of education becomes crucial. In Ukraine where in the rural area we can still witness lack of such digital tools as laptops and tablets the problem is to arise and to cause possible innovation crisis because of lack of people able to manipulate the innovative technique and equipment.

To meet the challenges of digitalization of agrarian sector and create conditions for effective human development it is necessary to provide a well-grounded Government policy.

\section{DISCUSSION}

The digitalization of agrarian sector is the main trend in the current condition, something that cannot be avoided or escaped. The choice not to implement digital technologies into the sector can cause widening of the gap between the Ukrainian economy and economy of the developed countries of the world. Taking into consideration the crucial role of the agrarian sector in the economy of Ukraine the process of implementing digital technologies in it should become the priority.

Implementing the digital technologies into the sector helps to solve not only the economic goals of the agrarian companies in particular and of the sector as a whole but it allows solving the human development problems, raising quality of life of people, improving their mentality.

However digitalization of the agrarian sector provided fast can cause resistance on behalf of people because of their reluctance to changes, to studying, and to new forms of management. That is why practical providing of digital modernization should be a well-thought and evolutionary process attended by simultaneous workers' training.

\section{CONCLUSIONS}

So that digitalization of agrarian sector plays a very important role in current conditions in Ukraine as well as in other countries of the world. This is due to the facts that on the one hand nowadays the agrarian sector can be considered

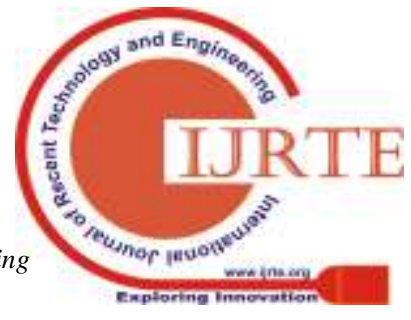


a locomotive of the Ukrainian economy; on the other hand digitalization is a process that brings qualitative changes in all spheres of life raising both economic and human development. Digitalization of agribusiness is a task set by major market players and industry leaders. It is important for them to get stably high yields at optimal costs, to produce high-quality, but at the same time cheap products. And high technology plays a key role in this. Simultaneously thanks to digitalization life of people alters qualitatively, new working places are being created, the way of thinking of people changes and the life standards rise.

Today we can witness a lot of important new innovations and technologies introduced by representatives of big agrarian companies and implemented into the process of production of the agrarian goods. But the main problem that arises here is low preparation of people in the rural areas to manipulate these technical achievements. The solution to the problem is providing of Government supportive programs for lifting the e-literacy of people in the villages, facilitating of conditions and creating digital culture.

Practical implications. The results of the research can be used as a source of information concerning the steps in digitalization of agrarian sector in order to provide proper economic and human development.

\section{REFERENCES}

1. Agricultural sector of Ukraine, 2018. Securing the global food supply. Available at: file:///C:/Users/User/Downloads/agro-small.pdf. (accessed 12 September, 2019)

2. Digital technologies in Agriculture. Briefing paper, 2019. Food and Agriculture Organization of the United Nations. Rome. Available at: http://www.fao.org/3/ca4887en /ca4887en.pdf (accessed 12 September, 2019)

3. Elektronic commerce-2018: what will the Ukrainians buy on-line next year, 2018. Available at: https://24tv.ua/elektronna_komertsiya_v_ukrayini_2018_ shho_kupuvatimut_online_v_ukrayini_n903265 (accessed 12 September, 2019)

4. Fifty shadows of digitalization, 2019. Available at: https://agroreview.com/news/50-vidtinkiv-didzhytalizaci yi ?page $=9$ (accessed 12 September, 2019$)$

5. Guests from the future: innovational systems of agroholdings' management, 2016. Available at: https://latifundist.com/spetsproekt/257-gosti-iz-budushch ego-innovatsionnye-sistemy-upravleniya-agroholdingami (accessed 13 September, 2019)

6. How the Ukrainian agro sector transferred from kolkhoz to the modern IT - solutions. 2016. Available at: https://delo.ua/business/kak-ukrainskij-agrosektor-peresh el-ot-sovetskih-kolhozov-k-sovre-323259/ (accessed 12 September, 2019)

7. Kozhemiakina, S., Cherkasov, A., Reznik, N., Zhuravka, O., Mazurov, S New workplace forecasting in the industrial sector of the Ukrainian economy. Problems and Perspectives in Management, 16 (4), p. 384 - 394, 2018. Available at : https://www2.scopus.com /authid/detail.uri?authorId=57202444035

8. Lazebnyk, L. Digitalization of economic relations as a factor of improving the business processes at the enterprise, 2, p. 69 - 74, 2018. Ekonomichnyi visnyk. Seriia: finansy, oblik, opodatkuvannia, Available at: http://ojs.nusta.edu.ua/index.php/ojs1/article/view/75

9. Negroponte, N. Being digital. Mackays of Chatham PLC, London, Great Britain, 1995. Available at
http://governance40.com/wp-content/uploads/2018/12/Ni cholas-Negroponte-Being-Digital-Vintage-1996.pdf]

10. Reznik, N., Gupta, S., Sakovska, O., Ostapchuk, A. Levkina, R. (2019) Ukrainian world exchange market of oilseeds: A research of challenges for growth. International Journal of Engineering and Advanced Technology, 8(6), p. 3823 - 3829. Available at:: https://www2.scopus.com/authid/detail.uri?authorId=572 02444035 